\title{
Changes in Free Amino Acid Composition Caused by Lipid Oxidation in Pulverized Niboshi (Boiled and Dried Anchovy) during Storage
}

\author{
Akihide Takiguchi \\ Chiba Prefectural Fisheries Experimental Station, Chikura, Awa, Chiba 295, Japan \\ (Received April 17, 1995)
}

\begin{abstract}
Niboshi (boiled and dried anchovy) was prepared from fatty and lean raw materials, pulverized, packed in a plastic pouch with and without an oxygen absorber, then stored at 25 and $-20^{\circ} \mathrm{C}$ for 60 days. Lipid oxidation and changes in the free amino acid compositions of the pulverized niboshi during storage, were investigated.

In the fatty samples, lipid oxidation and brown discoloration significantly occurred during storage at $25^{\circ} \mathrm{C}$. At the same time, the contents of the free amino acids such as taurine, glutamine, methionine, histidine, and lysine decreased. In contrast, in the lean sample, lipid oxidation and brown discoloration only slightly occurred during storage at $25^{\circ} \mathrm{C}$. The taurine content remained unchanged during storage. When packed with an oxygen absorber, both the fatty and lean samples were effectively protected from lipid oxidation during storage, though a brown discoloration developed with decreases in the glutamine and histidine contents. In the case of storage at $-20^{\circ} \mathrm{C}$, lipid oxidation in both the fatty and lean samples proceeded gradually. However, the brown discoloration was not observed throughout the 60-day storage.

From these results, it was presumed that methionine was decomposed by the action of the lipid peroxides, histidine, lysine, and taurine that reacted with the carbonyl compounds produced during the course of oxidative degradation of the lipids to form brown pigments, while glutamine decreased at room temperature.
\end{abstract}

Key words: niboshi, oxidation, free amino acid, lipid

Pulverized niboshi (boiled and dried anchovy) is used as soup stock because of its desirable flavor. The main components for improving the flavor of the soup are inosinic acid and certain free amino acids. ${ }^{1)}$ Since pulverized niboshi contains lipids composed of highly unsaturated fatty acids at relatively high proportions, it sometimes undergoes deterioration caused by lipid oxidation during storage $;^{2)}$ a brown discoloration develops and the flavor is degraded due to lipid oxidation. Therefore, pulverized niboshi is usually stored in a refrigerator or packed with an oxygen absorber to protect it from deterioration.

The brown discoloration seems to be caused by the Maillard reaction between lipid oxidation products including carbonyl compounds and amino compounds including free amino acids. ${ }^{3-6)}$ Nakamura et al $^{7}$ reported the reaction of lysine with some lipid oxidation products that formed brown pigments. Natake et al ${ }^{8)}$ showed that lipid peroxides reacted with methionine. The author ${ }^{9)}$ demonstrated in a previous paper that as lipid oxidation proceeded in niboshi, the contents of methionine, histidine and lysine decreased and the brown discoloration developed during storage.

In this study, the relationships between lipid oxidation, brown discoloration and changes in free amino acid composition of niboshi were investigated using pulverized lean and fatty niboshi to elucidate the mechanism involved in the deterioration of pulverized niboshi.

\section{Materials and Methods}

\section{Materials}

Two groups of anchovy Engraulis japonicus were used as raw materials to produce niboshi. One was the fatty anchovy (average body length, $8.9 \mathrm{~cm}$; average weight, $5.2 \mathrm{~g}$; average lipid content, $4.1 \%$ ) which was landed at the Kamogawa fisheries port in Chiba prefecture and the other was the lean anchovy (average body length, $7.2 \mathrm{~cm}$; average weight, $2.6 \mathrm{~g}$; average lipid content, $0.7 \%$ ) which was held as stock trapped in a fishing net in Tateyama Bay, Chiba prefecture. The average body length and weight were calculated from fifty samples. The average lipid content was calculated from five samples. The anchovy was boiled in a $3 \%$ salt solution at $90-95^{\circ} \mathrm{C}$ for $5 \mathrm{~min}$ and then dried at $25^{\circ} \mathrm{C}$ in a model KD-21A dryer (Kuchoshouji Co., Ltd.). In the case of the lean anchovy, drying was continued for up to $30 \mathrm{~h}$ and for the fatty anchovy, up to $50 \mathrm{~h}$. The boiled and dried anchovy (niboshi) thus prepared was then crushed to produce a powder below 120 mesh. Thus, two kinds of pulverized niboshi of different lipid contents of $14.5 \%$ (fatty sample) and $3.1 \%$ (lean sample) were prepared.

\section{Storage Conditions}

Approximately $300 \mathrm{~g}$ portions of the sample were put into polyethylene film pouches and stored at $25^{\circ} \mathrm{C}$ and $-20^{\circ} \mathrm{C}$ for 60 days. Another $100 \mathrm{~g}$ portion of the same sample was packed with an oxygen absorber in a laminate 
film (ON15/EF-F15/PE60) pouch, heat-sealed and stored at $25^{\circ} \mathrm{C}$ for 60 days.

\section{Color Measurement}

The $L, a$, and $b$ values, which are the indices of brightness, red hue and yellow hue of the sample, were measured with a model $\Sigma-90$ spectrocolor monitor (Nippon Denshoku Co., Ltd.).

\section{Extraction of Lipids}

Lipids in the niboshi sample were extracted with chloroform/methanol $(2: 1, \mathrm{v} / \mathrm{v})$ according to the method of Folch et al. ${ }^{10)}$

\section{Determination of Peroxide Value}

The peroxide value (PV) of the lipid was determined using the iodometric method. ${ }^{11}$

\section{Determination of Fatty Acid Composition}

The lipid was saponified with $1 \mathrm{M}$ alcoholic $\mathrm{KOH}$ at $85^{\circ} \mathrm{C}$ for $30 \mathrm{~min}$. After acidification of the reaction mixture with $\mathrm{HCl}$, free fatty acids were extracted with diethyl ether and converted to their methyl esters by using $14 \%$ $\mathrm{BF}_{3}$ in methanol. The fatty acid methyl esters were injected into a Shimadzu GC 9-A gas chromatograph equipped with a flame-ionization detector to determine the fatty acid composition. The conditions for the gas chromatography were as follows: column, SUPELCOWAX-10 fused silica capillary column, $0.25 \mathrm{~mm}$ i.d. $\times 30 \mathrm{~m}$ (Supelco Japan, Tokyo); column oven and injection port temperatures, $195^{\circ} \mathrm{C}$ and $250^{\circ} \mathrm{C}$, respectively; flow rate of carrier gas (He), $20 \mathrm{ml} / \mathrm{min}$.

\section{Determination of Oxygen Absorption}

An appropriate amount of the sample $(1.0 \mathrm{~g}$ and $0.5 \mathrm{~g}$ for the lean and fatty samples, respectively) was placed in a $15 \mathrm{~m} /$ gas-tight glass vial, sealed with a cap and stored at $25^{\circ} \mathrm{C}$ and $-20^{\circ} \mathrm{C}$. The oxygen concentration of the headspace air in the vial was analyzed using a Shimadzu GC 9A gas chromatograph equipped with a thermal conductivity detector. The conditions for the gas chromatography were as follows: column, glass tubing ( $3 \mathrm{~mm}$ i.d. $\times 2 \mathrm{~m}$ ) packed with Molecular Sieve 13X (Shinwakako Co., Ltd., Kyoto, Japan); column oven and injection port temperatures, $90^{\circ} \mathrm{C}$ and $100^{\circ} \mathrm{C}$, respectively; flow rate of carrier gas $(\mathrm{He}), 50 \mathrm{ml} / \mathrm{min}$.

\section{Determination of Extractive Nitrogen and Free Amino Acid Composition}

Samples of pulverized niboshi were extracted with $80 \%$ ethanol. The total nitrogen of the extract was determined by the Kjeldahl method. The free amino acid was analyzed using a KLC-203 automatic amino acid analyzer (Atto Co., Ltd.).

The fatty acid composition of the pulverized niboshi before storage was based on the mean and standard deviation of five samples. The other results were the average of two samples.
The color of the niboshi samples during storage were visually observed. During storage at $25^{\circ} \mathrm{C}$, the fatty samples both in the unsealed pouch and in the sealed pouch with an oxygen absorber were tinged with brown. However, the color of the sample at $-20^{\circ} \mathrm{C}$ remained unchanged during storage. In the lean samples, the color changes were similar to those of the fatty samples.

The $L, a$, and $b$ values of the fatty and lean samples during storage are shown in Table 1 . In the fatty sample stored at $25^{\circ} \mathrm{C}$, the $\mathrm{L}$ value decreased up to 9 days of storage and then remained unchanged, while the $b$ value rapidly increased up to 9 days and slowly thereafter. The a value gradually increased throughout the storage period. When the fatty sample was packed and stored at $25^{\circ} \mathrm{C}$ with an oxygen absorber for 9 days, the $\mathrm{L}$ value decreased, though the $a$ and $b$ values increased. Thereafter, these three values remained almost unchanged. In contrast, in the fatty sample stored at $-20^{\circ} \mathrm{C}$, the $\mathrm{L}$, $a$, and $b$ values remained essentially unchanged throughout the storage period.

In the lean sample stored at $25^{\circ} \mathrm{C}$, the $\mathrm{L}$ and $\mathrm{b}$ values slowly increased throughout the storage period, but the a value remained almost unchanged. The $\mathrm{L}$ value of the lean sample packed and stored with an oxygen absorber at $25^{\circ} \mathrm{C}$ continuously decreased during storage, while the a value gradually increased. The $b$ value rapidly increased up to 9 days and then only slowly changed. When stored at $-20^{\circ} \mathrm{C}$, the lean sample showed no obvious changes in its $L, a$, and $b$ values. These results were similar to those of the fatty sample.

\section{Lipid Oxidation}

The changes in the PV of lipids in the niboshi samples during storage are shown in Fig. 1. The PV of the fatty

Table 1. Changes in L, a, and b values of the pulverized fatty and lean niboshi during storage

\begin{tabular}{|c|c|c|c|c|c|c|}
\hline \multirow{2}{*}{ Sample } & \multirow{2}{*}{$\begin{array}{c}\text { Storage } \\
\text { temperature }\end{array}$} & & \multirow{2}{*}{$\begin{array}{l}\text { Before } \\
\text { storage }\end{array}$} & \multicolumn{3}{|c|}{ Storage (day) } \\
\hline & & & & 9 & 30 & 60 \\
\hline \multirow[t]{9}{*}{ Fatty niboshi } & & $\mathrm{L}$ & 43.1 & 40.9 & 40.5 & 40.3 \\
\hline & $25^{\circ} \mathrm{C}$ & $\mathbf{a}$ & 0.0 & 1.7 & 3.4 & 3.9 \\
\hline & & $\mathrm{b}$ & 9.9 & 14.3 & 15.9 & 16.2 \\
\hline & $25^{\circ} \mathrm{C}$ & $\mathbf{L}$ & 43.1 & 38.6 & 37.6 & 37.4 \\
\hline & (Packed with & $\mathrm{a}$ & 0.0 & 1.5 & 2.4 & 2.6 \\
\hline & oxygen absorber) & $b$ & 11.9 & 11.9 & 12.5 & 12.5 \\
\hline & & $\mathbf{L}$ & 42.9 & 42.9 & 43.8 & 45.0 \\
\hline & $-20^{\circ} \mathrm{C}$ & $\mathbf{a}$ & 0.1 & 0.1 & 0 & -0.1 \\
\hline & & $\mathrm{b}$ & 9.9 & 9.9 & 10.2 & 10.2 \\
\hline \multirow[t]{9}{*}{ Lean niboshi } & & $\mathrm{L}$ & 41.6 & 43.0 & 43.8 & 44.2 \\
\hline & $25^{\circ} \mathrm{C}$ & a & 0.3 & 0.1 & 0.2 & 0.2 \\
\hline & & $b$ & 5.8 & 7.4 & 8.2 & 9.1 \\
\hline & $25^{\circ} \mathrm{C}$ & $\mathrm{L}$ & 41.6 & 43.0 & 42.4 & 41.5 \\
\hline & (Packed with & $\mathrm{a}$ & 0.3 & 0.3 & 0.6 & 0.8 \\
\hline & oxygen absorber) & $\mathrm{b}$ & 5.8 & 7.1 & 7.5 & 7.5 \\
\hline & & $L$ & 41.6 & 43.0 & 43.3 & 42.6 \\
\hline & $-20^{\circ} \mathrm{C}$ & a & 0.3 & 0.1 & 0.2 & 0.2 \\
\hline & & $\mathrm{b}$ & 5.8 & 5.8 & 5.8 & 6.1 \\
\hline
\end{tabular}




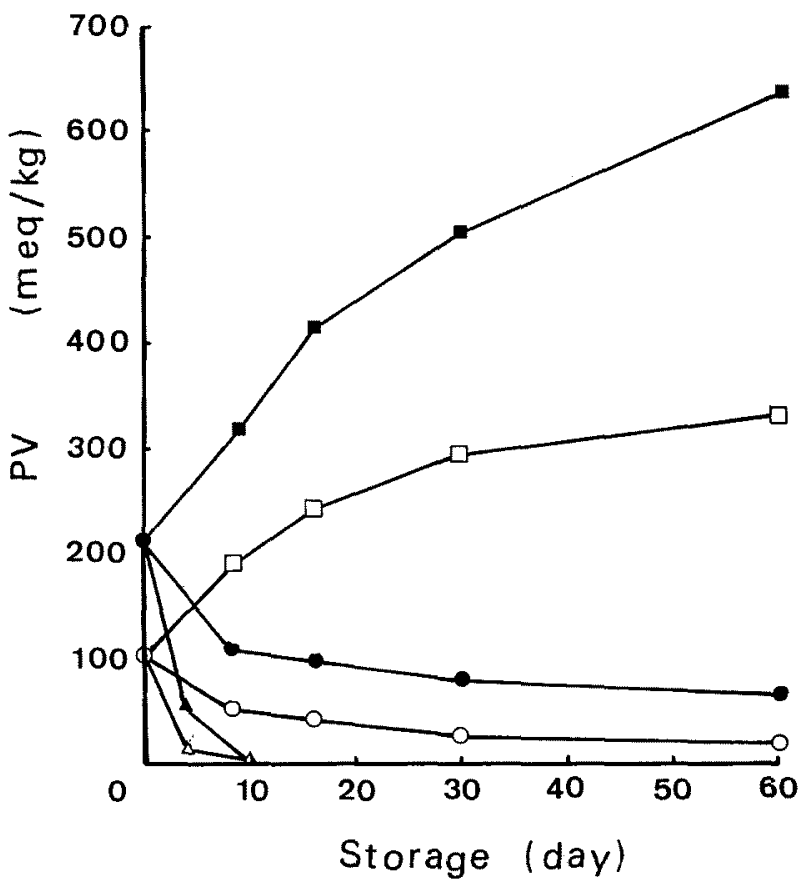

Fig. 1. Changes in peroxide value (PV) of the lipids extracted from pulverized fatty and lean pulverized niboshi during storage.

- - pulverized fatty niboshi stored at $25^{\circ} \mathrm{C} ;-\mathbf{\Lambda}-$, pulverized fatty niboshi packed with oxygen absorber and stored at $25^{\circ} \mathrm{C} ;-$ - -, pulverized fatty niboshi stored at $-20^{\circ} \mathrm{C} ;-\mathrm{O}-$, pulverized lean niboshi stored at $25^{\circ} \mathrm{C} ;-\triangle-$, pulverized lean niboshi packed with oxygen absorber and stored at $25^{\circ} \mathrm{C} ;-\mathrm{Q}-$, pulverized lean niboshi stored at $-20^{\circ} \mathrm{C}$.

sample was $217 \mathrm{meq} / \mathrm{kg}$ before storage. This implies that lipid oxidation is already occurring during processing in pulverized niboshi. When stored at $25^{\circ} \mathrm{C}$, the fatty sample showed a decrease in the PV during storage. In the sample packed with an oxygen absorber, PV rapidly decreased and was not measurable after 10 days storage. In contrast, the $\mathrm{PV}$ of the sample stored at $-20^{\circ} \mathrm{C}$ gradually increased and reached $636 \mathrm{meq} / \mathrm{kg}$ after storage for 60 days. In the lean sample, the PV of the lipid was $104 \mathrm{meq} / \mathrm{kg}$ before storage, which was lower than that of the fatty sample. During storage at $25^{\circ} \mathrm{C}$, the PV of the sample decreased throughout the storage period. The PV of the sample packed and stored at $25^{\circ} \mathrm{C}$ with an oxygen absorber also rapidly decreased and was not measurable after 10 days. However, when the lean sample was stored at $-20^{\circ} \mathrm{C}$, the $\mathrm{PV}$ increased in a pattern similar to that of the fatty sample stored at $-20^{\circ} \mathrm{C}$, but the PV of the lean sample was lower than that of the fatty sample throughout the storage period.

Figure 2 shows the changes in the oxygen absorption curves of niboshi samples during storage. The fatty sample rapidly absorbed oxygen during storage at $25^{\circ} \mathrm{C}$. However, the oxygen absorptions of the fatty sample stored at $-20^{\circ} \mathrm{C}$ and the lean samples stored both at $25^{\circ} \mathrm{C}$ and at $-20^{\circ} \mathrm{C}$ were all slow during storage for 60 days. Of these samples, the lean sample stored at $-20^{\circ} \mathrm{C}$ showed the lowest oxygen absorption value.

The fatty acid compositions of the lipids in the fatty and lean samples before storage are shown in Table 2 . The

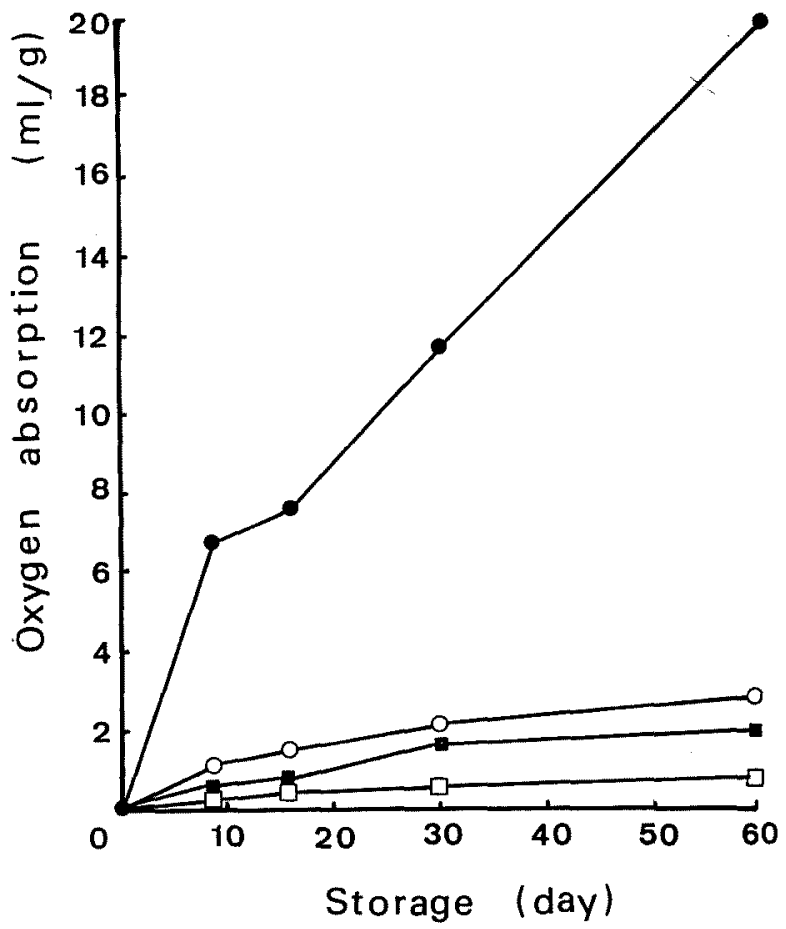

Fig. 2. Changes in oxygen absorption of the pulverized fatty and lean niboshi during storage.

- - pulverized fatty niboshi stored at $25^{\circ} \mathrm{C}$; - - , pulverized fatty niboshi stored at $-20^{\circ} \mathrm{C}$; $-\mathrm{O}-$, pulverized lean niboshi stored at $25^{\circ} \mathrm{C} ;-\square-$, pulverized lean niboshi stored at $-20^{\circ} \mathrm{C}$.

Table 2. Fatty acid compositons of the total lipids in pulverized fatty and lean niboshi before storage

\begin{tabular}{|c|c|c|}
\hline $\begin{array}{l}\text { Fatty } \\
\text { acid }\end{array}$ & $\begin{array}{l}\text { Fatty } \\
\text { niboshi }\end{array}$ & $\begin{array}{l}\text { Lean } \\
\text { niboshi }\end{array}$ \\
\hline $14: 0$ & $7.9 \pm 0.3^{*}{ }_{1}$ & $4.8 \pm 0.2^{* 1}$ \\
\hline $14: 1$ & $0.2 \pm 0$ & $0.3 \pm 0$ \\
\hline $15: 0$ & $0.5 \pm 0$ & $0.5 \pm 0.1$ \\
\hline $16: 0$ & $24.8 \pm 0.4$ & $22.7 \pm 0.1$ \\
\hline $16: 1 \mathrm{n}-7$ & $7.3 \pm 0.2$ & $5.3 \pm 0.1$ \\
\hline $16: \ln -5$ & $0.2 \pm 0$ & $0.2 \pm 0$ \\
\hline $16: 2 n-4$ & $1.2 \pm 0$ & $1.1 \pm 0$ \\
\hline $16: 3 n-4$ & $1.3 \pm 0$ & $1.0 \pm 0$ \\
\hline $17: 0$ & $0.8 \pm 0.1$ & $0.9 \pm 0.1$ \\
\hline $18: 0$ & $3.4 \pm 0.3$ & $8.9 \pm 0.1$ \\
\hline $18: \ln -9$ & $8.3 \pm 0.2$ & $14.1 \pm 0.2$ \\
\hline $18: 1 n-7$ & $4.0 \pm 0.2$ & $2.9 \pm 0.1$ \\
\hline $18: 2 n-6$ & $1.1 \pm 0.1$ & $2.3 \pm 0$ \\
\hline $18: 2 n-4$ & $0.1 \pm 0$ & $0.3 \pm 0.1$ \\
\hline $18: 3 n-3$ & $0.2 \pm 0$ & $0.5 \pm 0.1$ \\
\hline $18: 4 n-3$ & $0.6 \pm 0$ & $0.5 \pm 0.2$ \\
\hline $20: 0$ & $0.7 \pm 0.1$ & $0.7 \pm 0$ \\
\hline $20: \ln -11$ & $1.4 \pm 0$ & $0.6 \pm 0$ \\
\hline $20: \ln -9$ & $0.7 \pm 0.2$ & $2.0 \pm 0$ \\
\hline $20: 2 n-6$ & $1.9 \pm 0.1$ & $1.1 \pm 0.1$ \\
\hline $20: 4 n-3$ & $0.7 \pm 0$ & $1.6 \pm 0$ \\
\hline $20: 5 n-3$ & $14.8 \pm 0.4$ & $6.5 \pm 0.2$ \\
\hline $22: 0$ & $0.1 \pm 0$ & $0.3 \pm 0$ \\
\hline $22: 1 \mathrm{n}-11$ & $2.0 \pm 0.2$ & $0.2 \pm 0$ \\
\hline $22: \ln -9$ & $0.6 \pm 0.1$ & $1.3 \pm 0$ \\
\hline $22: 5 n-6$ & $0.2 \pm 0$ & $0.4 \pm 0.1$ \\
\hline $22: 5 n-3$ & $0.6 \pm 0$ & $0.7 \pm 0$ \\
\hline $22: 6 n-3$ & $14.4 \pm 0.4$ & $18.3 \pm 0.2$ \\
\hline
\end{tabular}

*: Mean \pm standard deviation $(n=5)$. 


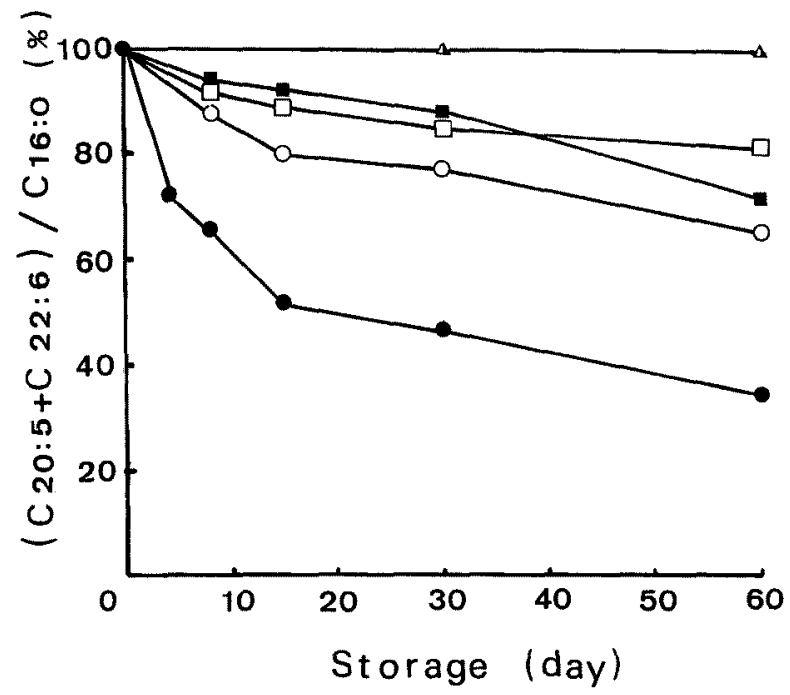

Fig. 3. Changes in ratios of polyunsaturated fatty acids (C20:5, C22:6) to palmitic acid in the lipid extracted from pulverized fatty and lean niboshi during storage.

- - pulverized fatty niboshi stored at $25^{\circ} \mathrm{C} ;-\mathbf{\Delta}-$, pulverized fatty niboshi packed with oxygen absorber and stored at $25^{\circ} \mathrm{C}$; - - w pulverized fatty niboshi stored at $-20^{\circ} \mathrm{C} ;-\mathrm{O}-$, pulverized lean niboshi stored at $25^{\circ} \mathrm{C}$; $-\triangle-$, pulverized lean niboshi packed with oxygen absorber and stored at $25^{\circ} \mathrm{C} ;-\square-$, pulverized lean niboshi stored at $-20^{\circ} \mathrm{C}$.

major fatty acids in the fatty sample were $\mathrm{C}_{16: 0}(24.8 \%)$, $\mathrm{C}_{20: 5}(14.8 \%), \mathrm{C}_{22: 6}(14.4 \%)$, and $\mathrm{C}_{18: 1}(12.3 \%)$ and those in the lean sample were $\mathrm{C}_{16: 0}(22.7 \%), \mathrm{C}_{22: 6}(18.3 \%)$, and $\mathrm{C}_{18: 1}$ $(17.0 \%)$. The fatty acid composition of the fatty sample was different in the percentage of $\mathrm{C}_{20: 5}$ from that of the lean sample, though the highly unsaturated fatty acids (HUFA) total such as $\mathrm{C}_{20: 5}$ and $\mathrm{C}_{22: 6}$ was high in both samples.

The changes in the HUFA percentage versus palmitic acid, $\left(\mathrm{C}_{20: 5}+\mathrm{C}_{22: 6}\right) / \mathrm{C}_{16: 0}$, are shown in Fig. 3. The HUFA ratio of the fatty sample stored at $25^{\circ} \mathrm{C}$ rapidly decreased, while that stored at $-20^{\circ} \mathrm{C}$ only slowly changed; the decreasing rate of the latter was markedly low. In the lean sample stored at $25^{\circ} \mathrm{C}$ and $-20^{\circ} \mathrm{C}$, the $\mathrm{HUFA}$ ratios decreased at a moderate rate during storage. The decreasing rate of the HUFA ratio was moderately lower in the lean sample than in the fatty sample. When the fatty and lean samples were packed with an oxygen absorber and stored at $25^{\circ} \mathrm{C}$, their HUFA ratios were almost unchanged during storage for 60 days.

\section{Changes in Free Amino Acid Composition}

The free amino acid compositions of the fatty and lean sample before and after storage are shown Table 3 . The major free amino acids in the fatty and lean samples were taurine, histidine, alanine and lysine. In the fatty sample packed with an oxygen absorber, glutamine, methionine and histidine contents decreased during storage at $25^{\circ} \mathrm{C}$ for 60 days. The methionine content also decreased after storage for 60 days at $-20^{\circ} \mathrm{C}$. Similar results were obtained for the lean sample.

The changes in extractive nitrogenous compounds during storage are shown in Fig. 4. In both the cases, pulver-
Table 3. Amino acid compositons of the pulverized fatty and lean niboshi before and after storage for 60 days at $-20^{\circ} \mathrm{C}$ and $25^{\circ} \mathrm{C} *$

\begin{tabular}{|c|c|c|c|c|c|c|}
\hline & \multicolumn{3}{|c|}{ Fatty niboshi } & \multicolumn{3}{|c|}{ Lean niboshi } \\
\hline & \multirow{2}{*}{$\begin{array}{l}\text { Before } \\
\text { storage }\end{array}$} & \multicolumn{2}{|c|}{ After storage } & \multirow{2}{*}{$\begin{array}{l}\text { Before } \\
\text { storage }\end{array}$} & \multicolumn{2}{|c|}{ After storage } \\
\hline & & $25^{\circ} \mathrm{C}^{*}$ & $-20^{\circ} \mathrm{C}$ & & $25^{\circ} \mathrm{C} *$ & $-20^{\circ} \mathrm{C}$ \\
\hline Taurine & 412 & 403 & 407 & 569 & 563 & 591 \\
\hline Aspartic acid & 17 & 15 & 17 & 7 & 7 & 7 \\
\hline Threonine & 19 & 20 & 18 & 14 & 14 & 15 \\
\hline Serine & 20 & 21 & 21 & 13 & 13 & 13 \\
\hline Glutamic acid & 39 & 41 & 41 & 28 & 26 & 29 \\
\hline Glutamine & 14 & 9 & 14 & 19 & 12 & 17 \\
\hline Proline & 38 & 38 & 38 & 31 & 26 & 34 \\
\hline Glycine & 23 & 22 & 23 & 29 & 29 & 27 \\
\hline Alanine & 80 & 83 & 83 & 77 & 77 & 71 \\
\hline Valine & 29 & 30 & 30 & 24 & 24 & 24 \\
\hline Methionine & 9 & 6 & tr & 8 & 5 & 3 \\
\hline Isoleucine & 21 & 21 & 20 & 17 & 19 & 17 \\
\hline Leucine & 42 & 45 & 43 & 34 & 35 & 36 \\
\hline Tyrosine & 19 & 21 & 20 & 14 & 15 & 14 \\
\hline Phenylalanine & 19 & 19 & 19 & 16 & 16 & 16 \\
\hline Histidine & 258 & 202 & 251 & 288 & 197 & 286 \\
\hline Lysine & 59 & 55 & 55 & 56 & 51 & 56 \\
\hline Arginine & 22 & 24 & 20 & 14 & 14 & 16 \\
\hline
\end{tabular}

* Pulverized niboshi was packed with oxygen absorber.

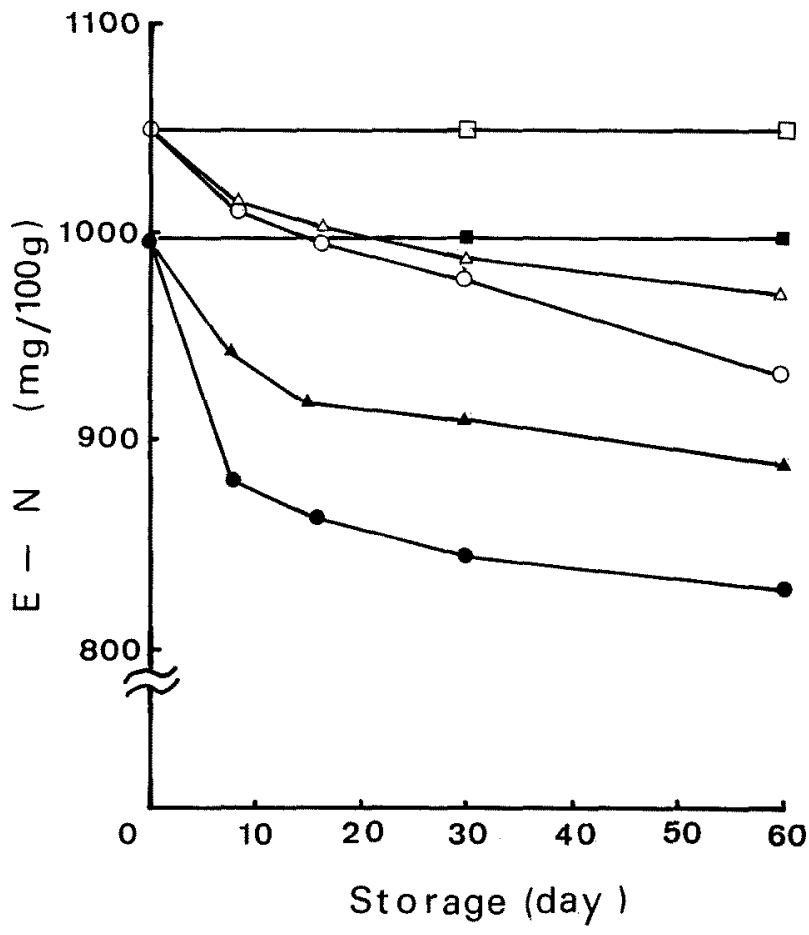

Fig. 4. Changes in extractive nitrogen $(E-N)$ in the pulverized fatty and lean niboshi during storage.

- - , pulverized fatty niboshi stored at $25^{\circ} \mathrm{C} ;-\boldsymbol{\Delta}-$, pulverized fatty niboshi packed with oxygen absorber and stored at $25^{\circ} \mathrm{C}$; - - pulverized fatty niboshi stored at $-20^{\circ} \mathrm{C}$; $-\mathrm{O}-$, pulverized lean niboshi stored at $25^{\circ} \mathrm{C}$; $-\Delta-$, pulverized lean niboshi packed with oxygen absorber and stored at $25^{\circ} \mathrm{C} ;-\square-$, pulverized lean niboshi stored at $-20^{\circ} \mathrm{C}$. 


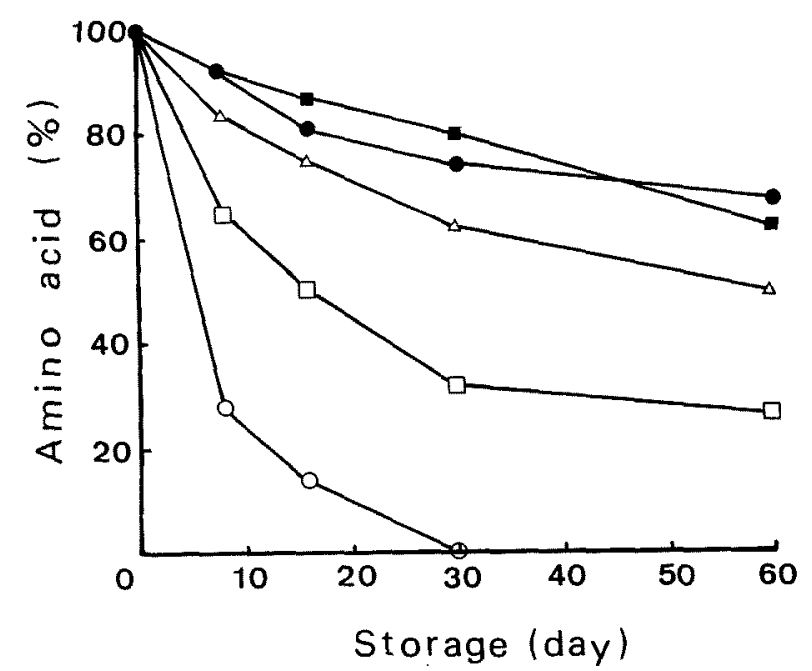

Fig. 5. Changes in percentages of the free amino acids remaining in the pulverized fatty niboshi during storage.

- -, taurine; - - glutamine; $\bigcirc-$, methionine; $ー \square-$, histidine; $-\Delta-$, lysine.

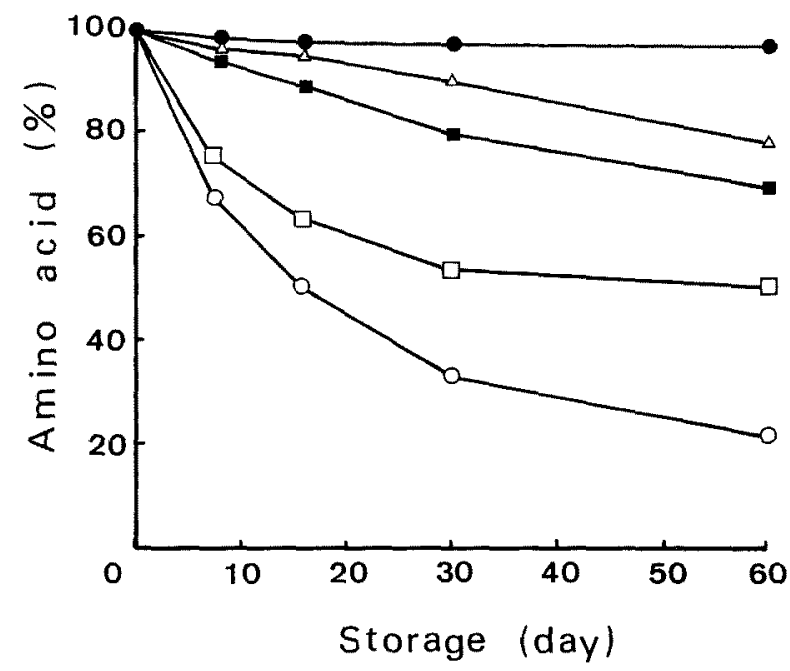

Fig. 6. Changes in percentages of the free amino acids remaining in the pulverized lean niboshi during storage.

- - , taurine; - - , glutamine; $-\mathrm{O}$, methionine; $\square-$, histidine; $-\triangle-$, lysine.

ized fatty niboshi and pulverized lean niboshi, the amount of extractive nitrogenous compounds did not change at $-20^{\circ} \mathrm{C}$ throughout the 60 days storage. At $25^{\circ} \mathrm{C}$, it decreased markedly regardless of the presence of the oxygen absorber. However, the decrease in the presence of oxygen absorber was somewhat slower than that without it.

The changes in free taurine, glutamine, methionine, histidine, and lysine contents in the fatty sample during storage at $25^{\circ} \mathrm{C}$ are shown in Fig. 5. Taurine, glutamine, methionine, histidine, and lysine decreased during storage. Methionine was not detected after storage for 30 days. The ratios of the other amino acids remaining after storage for 60 days were as follows: histidine; $26.3 \%$, lysine; $49.6 \%$, glutamine; $62.1 \%$, and taurine; $67.1 \%$.
The changes in free taurine, glutamine, methionine, histidine, and lysine contents in the lean sample during storage at $25^{\circ} \mathrm{C}$ are shown in Fig. 6. Glutamine, methionine, histidine, and lysine decreased during storage, but taurine remained unchanged. The ratios of these free amino acids remaining after storage for 60 days were as follows: methionine; $21.3 \%$, histidine; $50.2 \%$, glutamine; $68.9 \%$, lysine; $77.2 \%$, and taurine; $100 \%$.

\section{Discussion}

Pulverized niboshi is usually a brown color while stored at room temperature. The degree of brownness depends on the lipid content. Niboshi that has a higher lipid content tends to be more brown.

In this study, the fatty niboshi sample with a $14.5 \%$ lipid content was brown after the 60 -day storage at $25^{\circ} \mathrm{C}$. On the other hand, the lean niboshi sample with a $3.1 \%$ lipid content showed almost no brown color after 60-day storage at $25^{\circ} \mathrm{C}$. Both the fatty and lean niboshi samples stored at $-20^{\circ} \mathrm{C}$ were unchanged in color. The niboshi samples packed in an air-tight laminate film bag with an oxygen absorber stored at $25^{\circ} \mathrm{C}$ changed slightly to a reddish brown.

Lipids of the fatty and lean niboshi samples were rapidly oxidized during storage at $25^{\circ} \mathrm{C}$. The lipid oxidation that occurred in the fatty niboshi sample was somewhat faster than that in the lean niboshi sample. The PV showing the amount of peroxide liberated from the fish lipid and the intensity of the lipid oxidation was usually correlated to the lipid oxidation of the niboshi sample stored at $-20^{\circ} \mathrm{C}$ in this study. Since the niboshi lipid seemed to be oxidized too fast when evaluated by oxygen absorption or by changes in the fatty acid composition, the peroxide value was not a good index of lipid oxidation for the niboshi samples stored at $25^{\circ} \mathrm{C}$. A low storage temperature $\left(-20^{\circ} \mathrm{C}\right)$ prevented lipid oxidation of the niboshi sample. The oxygen-free package also prevented lipid oxidation even during storage at $25^{\circ} \mathrm{C}$ for 60 days.

Lipid oxidation that occurs in dried fish products usually causes an orange color on the surface of the products and a sour smell. These phenomena are generally called "aburayake" in Japanese. Many studies ${ }^{13-15)}$ about "aburayake" reported that amino compounds in the fish muscles react with carbonyl compounds liberated from the fish lipids caused by lipid oxidation. In the study, the contents of glutamine, methionine, histidine, lysine, and taltrine decreased and the niboshi sample turned brown with storage time. It is suggested that some free amino acids in the niboshi samples reacted with the carbonyl compounds liberated from the lipid oxidation and caused the brown discoloration. There has been much information ${ }^{8)}$ on the reaction of methionine with the peroxides of unsaturated lipids. In the pulverized niboshi, methionine decreased as lipid oxidation progressed. Glutamine in the niboshi samples which were unpacked and packed with an oxygen absorber decreased at $25^{\circ} \mathrm{C}$. The rates of decrease of glutamine in both the fatty and lean sample stored at $25^{\circ} \mathrm{C}$ were almost the same. Therefore, it is suggested that glutamine in the niboshi sample is unstable at room temperature. Histidine and lysine also decreased during storage. These two amino acids ${ }^{16)}$ seem to react with carbonyl compounds 
produced by the lipid oxidation to form some brown pigments, which cause the brown discoloration of pulverized niboshi to develop. The decrease in taurine that occurred in the fatty niboshi sample stored at $25^{\circ} \mathrm{C}$ suggested that taurine reacted with carbonyl compounds ${ }^{17}$ produced from the lipid oxidation.

Lipid oxidation in the pulverized niboshi during storage rapidly progressed, especially in the fatty sample. Pulverized niboshi should be packed in a pouch with an oxygen absorber and stored at low temperature to prevent lipid oxidation and to maintain its the desirable flavor and high nutrient value.

Acknowledgments I wish to thank Professor C. Koizumi of the Tokyo University of Fisheries for his valuable advice.

\section{References}

1) S. Konosu and K. Hashimoto: Suisanriyoukagaku, Kouseisyakouseikaku, Tokyo, 1992, pp. 119-120.

2) A. Takiguchi: Effects of smoking on lipid oxidation in niboshi and niboshi Powder. Nippon Suisan Gakkaishi, 54, 869-874 (1988).

3) C. Koizumi, S. Kurobe, and J. Nonaka: On the browning of dried fish products, Nippon Suisan Gakkaishi, 25, 368-372 (1959).

4) T. Nakamura: Occurence of red pigment-forming substances during autoxidation of lipids. Nippon Suisan Gakkaishi, 50, 477-479 (1984).

5) T. Nakamura and Y. Hama: Conjugated carbonyls with a prostaglandin-like structure formed by autoxidation of eicosapentaenoate. Nippon Suisan Gakkaishi, 54, 271-275 (1988).

6) A. Takiguchi and M. Yamaguchi: Antioxidative effect of brown pigment produced by lipid oxidation in boiled and dried anchovy.
Bull. Chiba Pref. Fish. Exp. Sta., 51, 75-79 (1993)

7) T. Nakamura, M. Toyomizu, and T. Sasaki: Discoloration reaction of dimer from autoxidized methyl linoleate with. lysine. Nippon Suisan Gakkaishi, 42, 777-782 (1976).

8) M. Natake and G. Danno: Autoxidative action of methionine in the autoxidation of linoleic acid. J. Jap. Soc. Food and Nutr., 26, 245250 (1973).

9) A. Takiguchi: Lipid oxidation and brown discoloration in niboshi during storage at ambient and low temperatures. Nippon Suisan Gakkaishi, 58, 489-494 (1992).

10) J. Folch, M. Lee, and G. H. Sloane-Stanley: A simple method for the isolation and purification of total lipid from animal tissues. $J$. Biol. Chem., 226, 497-509 (1957).

11) Japan Oil Chemists' Society ED., Standard methods for the analysis of oil and fats, Japan Oil Chemists' Society, Tokyo, 1972, pp. 2.4.12-71

12) T. Shono and M. Toyomizu: Changes in fatty acids constituting in fish muscle during storage at low temperature $\left(5^{\circ} \mathrm{C}\right)$. Nippon Suisan Gakkaishi, 37, 912-918 (1971).

13) J. Nonaka: Studies on the chemical essentials to the discoloration of fish-oil. Journal of the Tokyo University of fisheries, 43, 127-165 (1957).

14) M. Toyomizu and C. Y. Chung: Studies on discoloration of fishery products-V. Nippon Suisan Gakkaishi, 34, 857-862 (1968).

15) K. Fujimoto, J. Saito, and T. Kaneda: Studies on the brown discoloration of fish products-III. Nippon Suisan Gakkaishi, 37, 44-47 (1971).

16) M. Toyomizu, T. Yamazaki, and Y. Komori: Studies on discoloration of fishery products-IV. Nippon Suisan Gakkaishi, 34, 853-856 (1968).

17) A. Takiguchi: Discoloration of seasoned dried filefish during storage. Bulletin of Chiba Prefectural Fisheries Experimental Station, 49, 49-53 (1991). 